\title{
Property and the Public Domain
}

\author{
Hanoch Dagan*
}

\section{INTRODUCTION}

Friends of the public domain are typically suspicious of property-talk. Property is perceived as the foe, epitomizing the threat of a shrinking public domain. This common view is misguided; it is also unfortunate. It is misguided because the cleavage between property discourse and a thriving public domain is largely illusory. It is unfortunate because the concept of property has enormous rhetorical power in shaping people's expectations and therefore in the construction of what they deem normal, obvious, and thus clearly justified. ${ }^{1}$ For both reasons, friends of the public domain should embrace property, rather than fight it.

Lawrence Lessig's work epitomizes the suspicion of public domain advocates towards property. In Re-crafting a Public Domain Lessig laments the expanding rights of copyright holders to preclude others from using cultural artifacts and offers strategies for reversing the tide. Lessig claims that once classified as property, copyright is burdened by "the ordinary view about property" which is "binary at its core."2 He believes that notwithstanding lawyers' understanding of property as a bundle of rights, the propertization of creative activity facilitates a social ecology in which you must secure permission before your use. This ecology (alongside the powerful interest groups supporting it) accounts for Lessig's pessimism about the possibility of a happy legal reform. It also explains his apologetic response to critics of the attempt to encourage authors to opt into a system where only some of the rights copyright

Professor, Tel-Aviv University Faculty of Law. Thanks to Bruce Ackerman, Jack Balkin, Stuart Banner, Yochai Benkler, Michael Birnhack, Oren Bracha, Niva Elkin-Koren, Wendy Gordon, Michael Heller, Roy Kreitner, Larry Lessig, Menny Mautner, Robert Merges, Neil Netanel, Gideon Parchomovsky, Guy Pesach, Issi Rozen-Zvi, David Schorr, Tal Zarsky, and participants of the Yale Journal of Law \& Humanities' Carol Rose Symposium and the Tel-Aviv University Faculty of Law's Private Law Forum for helpful comments and to the Cegla Center for Interdisciplinary Research of the Law for financial support.

1. See, e.g., Laura S. Underkuffler, On Property: An Essay, 100 YALE L.J. 127, 146-47 (1990).

2. Lawrence Lessig, Re-crafting a Public Domain, 17 YALE J.L. \& HUMAN. 56, 81 (2006). 
secures are typically reserved. ${ }^{3}$

Neither the pessimism nor the apologia is warranted. Nothing in the language of property necessarily invites the agenda of the content industry. Quite the contrary: the form, the substance, and the history of property convey lessons that are rather helpful to the goal, which I share, of re-crafting the public domain. By neglecting these lessons, guardians of the public domain allow copyright expansionists to capture the powerful brand-name of property, ${ }^{4}$ thus undermining their very own cause.

\section{INSTITUTIONS}

The imagined war between property and the public domain begins with a dichotomy between lawyers' conception of property as a bundle of rights and its lay understanding as exclusion. ${ }^{5}$ The former view was never fully accepted in popular consciousness, so the argument goes, and therefore the latter must have won people's minds, entailing a set of devastating consequences for the increasingly propertized realm of creative activity. The validity of this argument depends on the plausibility of the conceptual choice it presents. Fortunately, this choice is as flawed as it is pervasive in property scholarship.

Neither the conception of property as exclusion nor that of property as a bundle bears any resemblance to the law of property as lawyers know it, or -even more importantly-as citizens experience it in everyday life. We should thus discard both of these conceptions of property and adopt one that is more in line with property's real life manifestations. Happily, as we will see, this understanding of property is hospitable to the purpose of reinvigorating a rich public domain.

Some measure of exclusion is, to be sure, part of what property usually entails. Yet, the conception of property as exclusion-understanding property law as the locus of a struggle between autonomous excluders, each cloaked in a Blackstonian armor of "sole and despotic dominion"6 is a great exaggeration. ${ }^{7}$ Exclusion can exhaust the field of property only if large parts of what is conventionally understood as the law of property are

3. Id. at 74, 78-81. See also LAWRENCE LeSSIG, FREE CULTURE 83-84, 117-19, 172 (2004).

4. In other words, the traditional linguistic lines of the copyright wars, in which expansionists label copyright as property and their opponents refer to it as a limited monopoly, may be part of the problem Lessig seeks to solve, and thus need to be addressed, rather than avoided. This does not mean that the monopoly effects of copyright and the deregulatory effects of an expanded public domain need to be ignored or that the role of public-domain discourse as a consciousness-creating concept be neglected. Rather, my claim is that defenders of the public domain should supplement, rather than supplant, their current line of argument with property reasoning.

5. The source, or at least an important milestone, of this dichotomy, is BRUCE A. ACKERMAN, PRIVATE PROPERTY AND THE CONSTITUTION (1977).

6. WILliam BLACKSTONE, 2 COMMENTARIES *2.

7. Equating property with exclusion also improperly bolsters the cultural power of libertarian claims. 
set aside. Numerous property rules, prescribing the rights and obligations of members of local communities, neighbors, co-owners, partners, and spouses cannot be fairly analyzed under the exclusion paradigm; the whole point of these elaborate doctrines, after all, is to provide structures for cooperative, rather than competitive, relationships. ${ }^{8}$ These doctrines are not marginal to the life of property. Rather, they deal with some of our most commonplace human interactions and thus tend to blend into our natural environment. Therefore, postulating exclusion as the lay understanding of property is not only condescending; it is also probably mistaken.

This failure of the exclusion conception of property does not mean that its "bundle of rights" counterpart is any more successful. Again, understanding property as a bundle has a grain of truth: property has no canonical composition, and therefore a reference to the concept of property can never entail an inevitable package of incidents. ${ }^{9}$ But property is not, as the bundle metaphor might suggest, a mere laundry list of rights with limitless permutations. Rather, as the numerus clausus principle prescribes, at any given time property law offers only a limited number of standardized forms of property. ${ }^{10}$ Not only do ordinary people not buy into the idea of open-ended bundles of rights; property law itself has never applied it either.

Rather than a uniform bulwark of exclusion or a formless bundle of rights, property should be thought of the way it actually is in both law and life: a set of institutions, each of which is constituted by a particular configuration of rights. The composition of entitlements that constitute each such property institution is determined (or at least should be determined) by its character and thus its underlying normative commitments. No technical competence is needed to see the basic thrust of the distinctions among the institutions of property. Leaving specifics aside, there is nothing mysterious about the different meanings of holding a traditional fee simple estate, owning a unit in a common interest community, or having a share in a publicly held corporation. Thus, there is no reason to think that these differences are not widely known and easily understood. In fact, law is justified in limiting the number of these property institutions exactly because of their role as default frameworks of interpersonal interaction that consolidate people's expectations and express law's normative ideals for core types of human relationships. ${ }^{11}$

8. See Hanoch Dagan \& Michael A. Heller, Conflicts in Property, 6 THEO. INQ. L. 37, 41 (2005).

9. See Wesley Newcomb Hohfeld, Fundamental Legal Conceptions as Applied in Judicial Reasoning, 26 YALE L.J. 710, 720, 733-34, 746-47 (1917).

10. See Thomas W. Merrill \& Henry E. Smith, Optimal Standardization in the Law of Property: The Numerus Clausus Principle, 110 YALE L.J. 1, 9-24 (2000).

11. I summarize here my extended discussion in Hanoch Dagan, The Craft of Property, 92 CaLIF. L. REV. 1517 (2003). 
Appreciating the multiple faces of property should relieve some of the concerns of public domain guardians and help direct their intellectual and public activity. Thus, rejecting property monism undermines the view, which Lessig takes seriously, that once creative activity is governed by a property regime-whatever its specific content may be-it necessarily becomes overly commercialized or carries overly individualistic connotations. In both law and life the repertoire of property institutions governs a wide array of types of social interactions, running from arm's length relationships guided by a competitive ideal, to familial relationships, where the ideal of equal sharing is the norm, with many intermediate categories along this spectrum. Indeed, the institutions of property are as diverse in their normative underpinnings as the categories of human interaction. The idea that the entitlements owners typically have in one type of property institution (governing, for example, commercial activity) necessarily apply with respect to others (such as those dealing with creative activity) is foreign to property law. It is also dramatically distant from the daily experience of property on the ground.

Therefore, instead of agonizing over the propertization of creativity, friends of the public domain should work toward a redefinition of the incidents of property rights in creative products, so that they properly respond to the normative concerns pertinent to the assignment of rights in information. ${ }^{12}$ This is the usual story of property dynamism: existing property institutions are constantly evolving, and new institutions are added (while others are dropped).$^{13}$ In the next section, I discuss the option of legal evolution. Here I address the notion of new property institutions.

I suggest analyzing the Creative Commons project as a new member of a proud tradition of property innovation. Like its predecessors, it is prompted by some dissatisfaction with the existing property institutions. The Creative Commons facilitates property rights in cultural artifacts that are very different from the defaults set by contemporary copyright law. As Lessig reports, the idea is to entrench a competing default that always preserves the right to attribution, but is more sensitive to the distinctions between derivative and non-derivative uses and between commercial and noncommercial uses. As usual with such property innovations, this may generate two happy outcomes: one is material (expanding the public domain), the other-expressive (educating people that "some rights

12. As usual, this inquiry should take into account the nature of the resource at stake, in our case information. Thus, for example, the fact that the consumption of information is nonrivalrous is crucial insofar as the consideration of providing appropriate incentives is concerned. See, e.g., Mark A. Lemley, Ex Ante versus Ex Post Justifications for Intellectual Property, 71 U. CHI. L. REV. 129, 143 (2004).

13. See Carol M. Rose, Property in All the Wrong Places?, 114 YaLE L.J. 991, 993, 1006, 1017 (2005). Property dynamism also involves a reexamination of the scope of the existing categories. In this context, one may ask whether at our time the category of copyright is too broad and needs to be divided. Exploring this question is beyond the scope of this short Comment. 
reserved" is the proper equilibrium of copyright). ${ }^{14}$ Lessig suggests that this new default is "crafted against the background of property law." 15 In fact, it is better analyzed as an attempt to reshape this very background. ${ }^{16}$

It is instructive to compare this project with the previous major bottomup property institution: the common interest community. After some resistance by courts and some adjustment of people's expectations, common interest communities are the fastest growing property institution in America. This property institution has already dramatically changed the reality of property for millions, as it typically entails features that are quite alien to the traditional fee simple absolute, notably the collective management of important aspects of a real-estate development and the thick layer of rules regarding the uses of individual units. The success of common interest communities in departing from the preexisting commonsensical understanding of the meaning of having a home demonstrates the potential of new property institutions. As the most recent major initiative to create a new property institution, the Creative Commons project can gain inspiration and encouragement from this success story.

\section{VALUES}

While new property institutions are added, existing property institutions are subject to an ongoing reconstructive inquiry, one in which lawyers identify and reevaluate their unifying normative ideals and the ways in which their particular configurations respond to these ideals. The yield of this process typically takes the form of a legal reform, aimed at allowing a property institution to live up to its own-existing or potential-ideals. (The judicial creation of the copyright misuse doctrine can serve as an example here. ${ }^{17}$ ) I do not mean to naïvely suggest that power and interests have had no role to play in the history of property. Powerful interest groups have indeed always been part of that drama. But as the reconstruction of both marital property law and of the law of leaseholds demonstrates, insofar as arguments have any role to play in this process, they typically push the landscape of property along the lines of this more

14. The Creative Commons' strategy is not flawless. In particular, it has been rightly criticized for lack of a clear normative message and excessive dependence on self restraint. See Niva ElkinKoren, Creative Commons: A Skeptical View of a Worthy Pursuit (unpublished manuscript, available at http://papers.ssm.com/abstract=885466). The project would better serve the goal of promoting a permission-free culture by offering stickier defaults and by allowing only licenses that are sufficiently friendlier to users than the current copyright default.

15. Lessig, supra note 2, at 82 .

16. Indeed, in order to fully succeed in its mission, the Creative Commons movement should aim at a legislative amendment that will offer "a uniform, widely understood standard practice" such as "an ' $\mathrm{L}$ in a circle' notice (for 'Limited Copyright Claimed-Full Copyright Waived')." See Robert Merges, A New Dynamism in the Public Domain, 71 U. CHI. L. REV. 183, 201-02 (2004).

17. See Dan Burk, AntiCircumvention Misuse, 50 UCLA L. REV. 1095, 1124-31 (2003). 
optimistic narrative. ${ }^{18}$

Lessig sketches three helpful suggestions for a legal reform that could support a permission-free culture: removing copying from the exclusive rights that copyright law grants, restoring formalities, and applying a modified Sullivan doctrine that would curtail the ability of copyright holders to preclude others from using their work as part of a commentary or criticism in matters of public import. But he is rather pessimistic about the possibility of their adoption. I am not competent to assess the existing political clout of the rival camps in the copyright wars. But I believe that given the cultural power of property, this pessimism may be premature because friends of the public domain have not yet used the intellectual support they could extract from property discourse. ${ }^{19}$ In the last section I address some specific property doctrines that may help. ${ }^{20}$ Here I discuss the more fundamental issue of property values, which are the engine of the optimistic story of property evolution.

As Lessig correctly maintains, the struggle over the scope and validity of the public domain involves important values. The values he invokes in supporting a protest against the shrinking of the public domain ${ }^{21}$ and in favor of the appropriate reforms include spreading culture, fostering creativity, and facilitating the efficient use of cultural artifacts. ${ }^{22}$ Lessig's neglect of some classic property values-notably desert and personhoodis both mistaken and regrettable. ${ }^{23}$

Failing to address these property values can be interpreted as an acknowledgement that these values support robust legal entitlements for copyright holders. But such a defeatist posture is unfounded because these normative commitments actually lead to a much more nuanced position. ${ }^{24}$

18. See Dagan, supra note 11 , at 1558-65.

19. The practical effect of having a better set of arguments depends on the role of ideals in the interest groups' competition for power, which is, I believe, more significant than is usually assumed. See Hanoch Dagan, Just Compensation, Incentives, and Social Meanings, 99 MICH. L. REv. 134 (2000). It remains to be seen whether this general observation also holds in the context of the copyright lobby. But skeptics should remember that the brute-power relations are a given, so that the only question is which language will do a better job in ameliorating them. Thus, if $I$ am correct as per the cultural power of property, then losing the property battle by default, and shifting to other, by hypothesis less powerful languages, needlessly exacerbates the predicament. (And if the skeptic's response is that here reasons are always overwhelmed by power, then the battle is bound to be lost in any event.)

20. For an elaborate exercise of borrowing from property law rules that limit, rather than expand, owners' dominion, see Michael A. Carrier, Cabining Intellectual Property Through a Property Paradigm, 54 DUKE L.J. 1, 52-144 (2004).

21. I take as a given the claim that the public domain is indeed shrinking. For an opposing view, see Julia D. Mahoney, Lawrence Lessig's Dystopian Vision, 90 VA. L. REV. 2305, 2319-20 (2004).

22. Lessig, supra note 2 , at $57-8,64,66-7$.

23. Lessig also makes frequent use of history, arguing that the current copyright regime "has no precedent in Anglo-American tradition." Lessig, supra note 2, at 66. But the fact that a property institution changes its face is, at most, only a weak argument against such a change. While some conservativism towards the existing property institutions is justified, essentializing the existing property institutions is certainly not. See Dagan, supra note 11, at 1558, 1560-61.

24. And, as I already mentioned above (supra note 4), there is no real price for engaging in this 
Particularly unfortunate is the failure to engage the desert for labor theory of property, given its strong popular appeal in contemporary society both generally ${ }^{25}$ and respecting the more specific context of assigning rights in intellectual products. ${ }^{26}$

To see the potential of this exercise we do not need to delve into Locke's articulation of that theory. ${ }^{27}$ It is enough to look at its most charitable (and rather intuitive) rendition. Property, in this view, is a reward for productive labor. Labor stands for people's efforts, perseverance, and risk-taking as well as-notwithstanding the daunting philosophical difficulties - the application of their innate intelligence and creativity. Productive labor means that not any exercise of energy would do-only purposeful activities, which are directed to useful ends, such as the preservation or comfort of our being. Laborers merit a reward because by engaging in value-creating activities they contribute to the betterment of the human predicament. ${ }^{28}$

If this is indeed the appeal that most people find in the labor theory of property, then they could easily see the three limitations of laborers' prerogatives that immediately follow. Laborers deserve rewards if and only if they engage in the right kind of activity (useful and purposeful, rather than destructive, inconsequential, or simply inadvertent). They can make a claim to be rewarded if and only if they have actually added value. ${ }^{29}$ And, finally, the deserved reward must be proportional to the added value they indeed generated. ${ }^{30}$

The second and third limitations are particularly significant for

inquiry: even if (arguendo) there was a good reason to resist analyzing the matter in terms of these property values, friends of the public domain should still use my claims as an alternative line of argument.

25. For some historical background, see David B. Schorr, Appropriation as Agrarianism: Distributive Justice in the Creation of Property Rights, 32 ECOLOGY L.Q. 3, 26-27 (2005).

26. The normative appeal of desert (and personhood) for any consideration of rights in intellectual products is not undermined by its dismissal from copyright legalese in Feist Publications, Inc. v. Rural Telephone Service Co., 499 U.S. 340, 352-56 (1991). I see this normative appeal as a sign that the attempt (of Lessig et al.) to build a high wall of autonomy from property ideas is both doomed to failure and intellectually misguided. Similarly to the unavoidable relationship of reciprocity between marital property law and other areas of both family law and property law, the law of creativity is rightly allied not only with fields of law that deal with speech, culture, and learning, but also with the more traditional areas of property law. Cf. Bruce A. Ackerman, The Structure of Subchapter C: An Anthropological Comment, 87 Y ALE L.J. 436, 438-39, 444 (1977).

27. On Locke's theory see, e.g., Jeremy Waldron, THE Right to PrIVATE Property 137-252 (1988); GOPal SREENIVASAN, THE Limits OF LOCKEAN Right IN PROPERTY (1995). There is a rich literature on the application of Locke's prescriptions to intellectual property. See, e.g., William Fisher, Theories of Intellectual Property, in NEW ESSAYS IN THE LEGAL AND POLITICAL THEORY OF PROPERTY 168, 184-89 (Stephen R. Munzer ed., 2001). Much of this literature uses Locke's famous proviso in order to counteract the harmful effect of an author's entitlement on future authors.

28. See Stephen Buckle, Natural Law AND the Theory of Property 149-52 (1991); STEPHEN R. MUNZER, A THEORY OF PROPERTY 255-56, 285-87 (1990).

29. A modified version may also allow such claims for unlucky good faith attempts to add value.

30. See Matthew H. KRAMER, John LOCKE AND THE ORIGINS OF PRIVATE PROPERTY 170-71 (1997); WALDRON, supra note 27, at 104-05. 
intellectual products. Creative activity always engages, invokes, and is inspired by - and thus vitally dependent upon-a cultural heritage: a range of preexisting cultural raw materials, and a set of established methods, practices and techniques. Therefore, even if we ignore the role of others, such as consumers, in prescribing the market value of intellectual products, ${ }^{31}$ the requirements of added value and proportionality imply that authors are unlikely to deserve this entire value. ${ }^{32}$

Because authors' reward should not take a proprietary form that allows them to extract the entire market value of their intellectual products, labor theory does not require that authors enjoy an indefeasible right to exclude. In particular, labor theory is compatible with (although it does not necessarily require) an IP regime that curtails in some cases the right to deny access, and limits copyright holders' material claims to some portion of the market value of their intellectual products, while insisting upon proper attribution as a necessary form of public praise and gratitude. ${ }^{33}$

\section{DOCTRINES}

Our discussion of property's institutions and property's values already lends some support to most of Lessig's suggested reforms, which take the form of tinkering with the existing bundle of rights that copyright entails. ${ }^{34}$ Thus, the attempt to renegotiate the content of copyright is by no means idiosyncratic: rethinking the configuration of the existing bundles that constitute our property institutions is part of the ebb and flow of property law. Moreover, even the most individualistic of property values-the desert for labor principle-allows constraining the entitlement of copyright holders. ${ }^{35}$

To be sure, Lessig and others have demonstrated stronger links between a happy copyright reform and other values, such as facilitating efficiency,

31. These factors are not unique to our context. In other words, whatever one may draw from the general dependence of laborers on the social infrastructure in which they operate is compounded by the more specific dependence relevant to intellectual products.

32. See Lawrence C. Becker, Deserving to Own Intellectual Property, 68 CHI.-KENT L. REV. 609, 624-26; Julie E. Cohen, Copyright, Commodification, and Culture: Locating the Public Domain (unpublished manuscript, available at http://papers.ssrn.com/abstract=663652); Wendy J. Gordon, $A$ Property Right in Self-Expression: Equality and Individualism in the Natural Law of Intellectual Property, 102 Yale L.J. 1533, 1556, 1561 (1993); Edwin C. Hettinger, Justifying Intellectual Property, in INTEllectual Property: MORAL, Legal and InTERNational Dilemmas 17, 22-23, 25 (Adam D. Moore ed., 1997); Sheana Valentine Shiffrin, Lockean Arguments for Private Intellectual Property, in NEW ESSAYS, supra note 27, at 138, 162.

33. The requirement of attribution is not only important from the standpoint of the property value of desert. Rather, it is a vital entailment of the property value of personhood.

34. Here I refer to two of Lessig's suggestions in Re-crafting a Public Domain-preventing authors from limiting mere copying and applying a modified-Sullivan defense-as well as to other suggestions he made elsewhere, notably shortening copyright's life. See LESSIG, supra note 3, at 29293.

35. See also NeIl Netanel, Copyright's Paradox: Property in EXPREssion/FreEdom of EXPRESSION (forthcoming 2006). 
enriching our culture, and nourishing democratic political institutions. ${ }^{36}$ But by situating these values outside property-let alone as counterproperty concerns-they undermine the force of these claims, making them too easily dismissible or discounted given the cultural power of property. ${ }^{37}$ Here again the divorce of public domain advocates from property is not only unfortunate but also erroneous. Just like labor (or personhood), these important concerns are better conceptualized as property values because they are part of the reason why we have rights in intellectual property in the first place. ${ }^{38}$ While it is understandable that copyright expansionists would want to exclude these concerns from property discourse, public domain advocates have no good reason to follow suit.

A similarly promising convergence between property discourse and the agenda of public domain preservation emerges regarding Lessig's last doctrinal suggestion: making copyright more formal. Both aspects of this suggestion-utilizing more clear rules and less vague standards, and strengthening copyrights' registration system-are indeed desirable. Both are supported by property law and theory. ${ }^{39}$

Property law has always been heavily-laden towards crystalline rules, as opposed to muddy standards. ${ }^{40}$ This is not surprising given the important property values served by clear entitlements. The predictability of such entitlements does not only serve efficiency; it is also conducive to liberty as it limits the application of discretion following various types of interaction. ${ }^{41}$ Likewise, the increasing value of intellectual products and the decreasing value of the costs of copyright registration make Lessig's claim for copyright registry a casebook example of property theory. ${ }^{42}$

36. On copyright and democracy see Neil Netanel, Copyright and a Democratic Civil Society, 106 YAle L.J. 283, 341-85 (1996). Cf. Niva Elkin-Koren, Cyberlaw and Social Change: A Democratic Approach to Copyright Law in Cyberspace, 14 CARDOZO ARTS \& ENT. L.J. 215 (1996).

37. This presentation is regrettable also because it perpetuates the impression that the property values against which these values are arguably raised do not entail any limitations of authors' rights.

38. Cf. Netanel, supra note 36, at 362-63. See also Carolyn J. Frantz \& Hanoch Dagan, Properties of Marriage, 104 COLUM. L. REV. 75 (2004) (addressing both community and equality as important property values which significantly shape marital property law).

39. These references to the broad category of property (like my prior discussion of property values) show that alongside the differences between the various institutions of property there are also important continuities. There are, in other words, family resemblances among the different property institutions.

40. See Carol M. Rose, Crystals and Mud in Property Law, 40 STAN. L. Rev. 577 (1988). Rose notes that muddied standards were always invoked in order to deal with cases of either notorious forfeiture or long-term dealings. Neither exception is relevant to our context.

41. Furthermore, as Lessig convincingly argues, a regime of vague standards undermines distributive justice. Lessig, supra note 2, at 58-9. Distributive justice is one more concern that is best analyzed in our context as a property value. See Hanoch Dagan, Takings and Distributive Justice, 85 VA. L. REV. 741 (1999).

42. See Terry L. Anderson \& P.J. Hill, The Evolution of Property Rights: A Study of the American West, 18 J. LAW \& ECON. 163 (1975); Douglass Baird \& Thomas Jackson, Information, Uncertainty, and the Transfer of Property, 13 J. LEGAL STUD. 299, 303-06 (1984); see also Ashton Hawkins et al., A Tale of Two Innocents: Creating an Equitable Balance Between the Rights of Former Owners and 


\section{CONCLUDING REMARKS}

In reflecting upon the continuity between traditional property law and the sphere of intellectual achievements, Carol Rose suggested. two important lessons: that the public domain and private property are not independent realms, but rather intimately intertwined; and that in both realms law should facilitate the flowering of an intermediate property institution along the lines of the liberal commons model. ${ }^{43}$ Rose is right on both fronts. As this Comment demonstrates, this continuity also generates a third lesson: that the defense-or revival--of a robust public domain can benefit from drawing on the rich intellectual resources that the institutions, values, and doctrines of property provide. Therefore, Lessig and his many fellow travelers-I count myself as one-should positively engage in property-talk, rather than grudgingly concede its unfortunate presence. ${ }^{44}$

Good Faith Purchasers of Stolen Art, 64 FORDHAM L. REV. 49 (1995).

43. Carol M. Rose, Romans, Roads, and Romantic Creators: Traditions of Public Property in the Information age, 66 L. \& CONTEMP. PROBS. 89, 101-02, 107 (2003). See also Carol M. Rose, The Several Futures of Property: Of Cyberspace and Folk Tales, Emission Trades and Ecosystems, 83 MINN. L. REV. 129, 155-62 (1998).

44. Another benefit of embracing property discourse is that it invites a discussion of the internal relationship between participants in the creative process, notably between suppliers of creative inputs (authors or creators) on the one hand and (typically corporate) copyright owners on the other hand. 